\title{
Highly Ordered 3D Silicon Micro-Mesh Structures Integrated with Nanowire Arrays: A Multifunctional Platform for Photodegradation, Photocurrent Generation, and Materials Conversion
}

Chang, Bingdong; Tang, Yingying; Liang, mingli; Jansen, Henri; Jensen, Flemming; Wang, Bo; Mølhave, Kristian; Hübner, Jörg; Sun, Hongyu

\section{Published in:}

ChemNanoMat

Link to article, DOI:

10.1002/cnma.201800371

Publication date:

2019

Document Version

Peer reviewed version

Link back to DTU Orbit

Citation (APA):

Chang, B., Tang, Y., Liang, M., Jansen, H., Jensen, F., Wang, B., Mølhave, K., Hübner, J., \& Sun, H. (2019). Highly Ordered 3D Silicon Micro-Mesh Structures Integrated with Nanowire Arrays: A Multifunctional Platform for Photodegradation, Photocurrent Generation, and Materials Conversion. ChemNanoMat, 5(1), 92-100. https://doi.org/10.1002/cnma.201800371

\section{General rights}

Copyright and moral rights for the publications made accessible in the public portal are retained by the authors and/or other copyright owners and it is a condition of accessing publications that users recognise and abide by the legal requirements associated with these rights.

- Users may download and print one copy of any publication from the public portal for the purpose of private study or research.

- You may not further distribute the material or use it for any profit-making activity or commercial gain

- You may freely distribute the URL identifying the publication in the public portal 
DOI: 10.1002/ ((please add manuscript number))

Full Paper

Highly Ordered 3D Silicon Micro-Mesh Structures Integrated with Nanowire Arrays: A Multifunctional Platform for Photodegradation, Photocurrent Generation, and Materials Conversion

Bingdong Chang *, Yingying Tang, Mingli Liang, Henri Jansen, Flemming Jensen, Bo Wang, Kristian Mølhave, Jörg Hübner and Hongyu Sun *

B. D. Chang, Prof. H. Jansen, Prof. F. Jansen, Prof. J. Hübner

DTU Danchip, Technical University of Denmark, Kongens Lyngby 2800, Denmark

E-mail:bincha@dtu.dk

Dr. Y. Y. Tang, M. L. Liang

Department of Chemistry, Technical University of Denmark, Kongens Lyngby 2800,

Denmark

Dr. B. Wang

Department of Mechanical Engineering, Section of Materials and Surface Engineering,

Technical University of Denmark, Kongens Lyngby 2800, Denmark

Prof. K. Mølhave, Dr. H. Y. Sun

Department of Micro- and Nanotechnology, Technical University of Denmark, Kongens

Lyngby 2800, Denmark

E-mail: hsun@nanotech.dtu.dk

Keywords: three dimensional structures; nanowire arrays; photocatalytic; photocurrent;

materials conversion

Abstract:

Hierarchical three dimensional (3D) microstructures integrated with low-dimensional nanomaterials can realize novel properties or improved performance. We report a unique conductive and highly ordered 3D silicon micro-mesh structure, which is fabricated by standard lithography using a modified plasma etch process. Zinc oxide ( $\mathrm{ZnO}$ ) nanowires are then integrated with the micro-mesh, and the density of $\mathrm{ZnO}$ nanowires (NWs) can be increased by around one order of magnitude compared with ZnO NWs on a 2D substrate. Owing to the high spatial density of ZnO NWs on the robust 3D silicon micro-mesh structures, improved photocatalytic activity and stability can be achieved. A remarkable enhancement of photocurrent response is also observed. The ZnO can be converted into ZnS NWs and 
ZnO@ZIF-8 as on the micromesh. This method is low-cost and compatible with traditional complementary metal-oxide-semiconductor industries, and provides new possibilities for a wide range of devices based on micro-nano-electro-mechanical and chemical systems.

\section{Introduction}

Materials with 3D structures and well-defined geometries can give performance improvements in applications within the fields of photonics ${ }^{[1]}$ and electronics ${ }^{[2]}$. First, intrinsic properties of the microstructured materials can be tuned in 3D structures, such as microporosity, and photonic bandgaps. Second, these 3D structures can be integrated with functional low-dimensional building blocks, e.g. nanoparticles or nanowires (NW), to achieve an improved performance of their desired functions. Although the potential of 3D structures is attractive, a reliable fabrication strategy is considered to be technically difficult. Bottom up synthesis of 3D foams constituted by metals $(\mathrm{Cu}, \mathrm{Ni}, \mathrm{Al}$, etc.) or graphene are widely used, however, the geometry and morphology of the 3D structures are difficult to control. Another category of top-down fabricated 3D structures employs traditional micro- and nanofabrication techniques from the semiconductor industry, which show the superiority for on-chip integration and mass production, albeit often at higher cost that will require a considerable performance improvements compared to bottom up systems.

To functionalize 3D microstructures, as a typical direct wide band gap $(\mathrm{Eg}=3.37 \mathrm{eV})$ semiconductor, zinc oxide $(\mathrm{ZnO})$ can generate free carriers by incident photons and be utilized for a wide range of purposes, e.g. dye sensitized solar cells (DSSC), ${ }^{[3]}$ photocatalytic reactions, ${ }^{[4]}$ supercapacitors, ${ }^{[5]}$ etc. Besides, the notable piezoelectric properties in $\mathrm{ZnO}$ nanostructures also makes it a good candidate for applications as electric generators ${ }^{[6]}$ and piezo-phototronic devices. ${ }^{[7]}$ Apart from the intrinsic physical and chemical properties, the geometry and morphology of $\mathrm{ZnO}$ nanostructures are important parameters that influence the above mentioned applications. By adjusting the nucleation and growth during the materials 
synthesis, $\mathrm{ZnO}$ nanostructures with a wide range of morphologies have been successfully achieved. ${ }^{[8-11]}$ Among these, $\mathrm{ZnO}$ NWs show unique advantages due to the facile fabrication process and the high spatial density, making ZnO NWs outperform other nanoscale counterparts in different applications, such as sensors ${ }^{[12]}$ and field electron emission. ${ }^{[13]}$

To further improve the materials usage and performance of $\mathrm{ZnO} \mathrm{NWs}$, increasing the spatial density of ZnO NWs on a device will facilitate the full contact of the NWs with the surrounding reaction medium, but also accelerate mass and ion transportation during device working. For example, Ko et al developed a repeated seed deposition-hydrothermal growth method to prepare long branched “treelike” multigeneration hierarchical ZnO NWs. Compared to the conventional $\mathrm{ZnO} \mathrm{NWs}$ without branches, the 3D $\mathrm{ZnO}$ nanotrees show a density increasement of 1-2 orders of magnitude, and 5 times improvement of the overall light-conversion efficiency for dye-sensitized solar cell. ${ }^{[14]}$ Another strategy is to use different 3D structures, i.e., graphene foams, ${ }^{[15,16]}$ nickel foams, ${ }^{[17]}$ or silicon NW arrays, ${ }^{[18]}$ as substrates for the growth of $\mathrm{ZnO} \mathrm{NWs}$, but often with low microstructure control mentioned above and process compatibility difficulties if on-chip integration is wanted.

Here we report a highly ordered 3D silicon micro-mesh structure, which is low cost and can be easily designed and fabricated, by being created in a single reactive ion etch run by a novel plasma etching technique. The fabricated silicon substrate has a mesh-like microstructure and can increase the surface area by around one order of magnitude compared to a 2D planar substrate. Importantly, the 3D silicon micro-mesh structures can be integrated with low-dimensional structures and become a promising platform for diverse applications. In this work, ZnO NWs were used as typical model system to demonstrate the usage of 3D silicon micro-mesh structures. Specifically, atomic layer deposition (ALD) was used to grow a $\mathrm{ZnO}$ layer conformally on the surface of the 3D silicon structures, to act as the seed layer for the following hydrothermal reaction, during which ZnO NWs were grown perpendicularly to the 3D mesh, forming a high density of ZnO NWs. The functionality was tested by 
photocatalytic degradation of rhodamine $\mathrm{B}(\mathrm{RhB})$ and photocurrent response properties of the obtained ZnO NWs/3D silicon structures and compared with that of ZnO NWs on 2D silicon substrates. A significant increase of degradation rate of RhB was observed under UV light irradiation, and the enhancement of light induced photocurrent was achieved. Thanks to the chemically and mechanically stable silicon substrate, the ZnO NWs can be used as selfsacrificed templates and chemically converted into other zinc-based compounds with tunable composition, such as zinc sulfide (ZnS) and zeolitic imidazolate frameworks (ZIF-8), while the original 3D NW morphology can still be inherited. Our results demonstrate the flexibility and multifunctionality of the fabricated NW arrays/3D silicon structures. It should be noted that the whole process is carried out at a relatively low temperature of below $200^{\circ} \mathrm{C}$, which is within the process limit of complementary metal oxide semiconductor (CMOS) circuits and most of the polymer materials, ${ }^{[19]}$ thus enabling flexibility and freedom for different applications. When integrating with CMOS devices, the proposed NW arrays/3D silicon structures are expected to show potentials in on-chip detection, power storage and conversion, and devices for in-situ thermal or electric modulations.

\section{Results and discussion}

\subsection{Fabrication and characterization}

A schematic view of the fabrication process flow is shown in Figure 1a, which includes pattern definition with conventional UV lithography, creation of 3D silicon microstructures with a new plasma etching process, ZnO layer coating with ALD, and the final step of hydrothermal reactions to grow ZnO NWs onto the 3D silicon structures. As a crucial step of the fabrication, highly ordered 3D silicon micro-mesh substrate was fabricated by the DREM (Deposit, Remove, Etch Multistep) method, which has been reported in our previous work. ${ }^{[20,}$

${ }^{21]}$ Briefly, DREM is a modified time multiplexed Bosch etch process, but employs well defined three steps and a parameter ramping technique, resulting in a straight profile of silicon 
structures. Meanwhile, sidewalls of the structure could be well protected by the fluorocarbon (FC) layer, which is generated by the passivation of octafluorocyclobutane $\left(\mathrm{C}_{4} \mathrm{~F}_{8}\right)$ gas. During the process, a few DREM cycles were first applied as in Figure 1a(2), thus an anisotropic silicon structure was fabricated. To make the structure isolated from substrate, an isotropic etch was applied as in Figure 1a(3), during which the FC layer on the sidewall could protect the structure from being corroded by the etch gas sulfur hexafluoride $\left(\mathrm{SF}_{6}\right)$. By repeating DREM cycles and isotropic etch, 3D multiple suspended layers could be fabricated as shown in Figure 1a(4), and the FC layer protected silicon structures acted as the etch mask for the next layer of suspended silicon structures. To prevent the isolated layers from collapse, some larger support structures were designed beforehand, which could survive the isotropic etch step and support the suspended silicon beams. After plasma ashing, the remaining photoresist layer and the FC layer on the silicon structures were removed, thus a clean highly ordered 3D silicon micro-mesh substrate was prepared for the subsequent ALD process, during which a $\mathrm{ZnO}$ layer with $50 \mathrm{~nm}$ thickness was deposited conformally as shown in Figure 1a(5). The ALD deposited ZnO thin film is polycrystalline with a major orientation of (002), ${ }^{[22]}$ and it will serve as the seed layer for the ZnO NWs growth via a hydrothermal reaction (Figure 1a(6)). ${ }^{[23,24]}$ Since ALD process is conformal, ZnO NWs would grow following the 3D silicon substrate, also on the bottom part of the suspended silicon structures. Thus ZnO NWs/3D silicon structures were fabricated, and the density of ZnO NWs could be increased compared with ZnO NWs on a 2D planar substrate.

The morphology of the highly ordered 3D silicon micro-mesh substrate and $\mathrm{ZnO}$ NWs/3D silicon structures were studied by scanning electronic microscope (SEM). Figure 1b shows the cross section view of 10 layered silicon microbeam structures , and the thickness of each beam is around $1 \mu \mathrm{m}$. The sample was cleaved and a tilted view is shown in Figure 1e. The length of the silicon microbeams is $10 \mu \mathrm{m}$ and the width is $2 \mu \mathrm{m}$, anchored on large pillars with $10 \mu \mathrm{m}$ diameter. After depositing $\mathrm{ZnO}$ seed layer and hydrothermal reactions, ZnO 
NWs can grow conformally following the surface of the silicon structures (Figure 1c, f). The length of ZnO NWs is controlled by the hydrothermal reaction time. The reaction time was carefully controlled to avoid the overlap of ZnO NWs between each two layers of silicon structures (Figure 1d, g).

Figure 2a shows a magnified SEM image of a single silicon microbeam covered by $\mathrm{ZnO}$ NWs. It can be seen that high density of ZnO NWs grow on the suspended silicon microbeam. Transmission electron microscope (TEM) image of the sample is shown in Figure 2b. The average length of the ZnO NWs is around $1 \mu \mathrm{m}$, and the diameter is $\sim 60 \mathrm{~nm}$. The crystalline and phase of the sample was determined by X-ray diffraction (XRD) as shown in Figure 2c. All the diffraction peaks are well matched with the wurtzite $\mathrm{ZnO}$ according to the standard diffraction card (JCPDS number: 36-1451). A strong (002) diffraction peak is observed, indicating the growth of $\mathrm{ZnO}$ NWs follows the crystalline orientation of ALD ZnO thin film. High-angle annular dark-field scanning transmission electron microscopy (HAADF-STEM) image and elemental mapping (Figure 2d) performed by electron dispersive x-ray (EDX) spectroscopy show the spatial distribution of Zn, O, and Si elements in the products. Additional structural characterizations with EDX, XRD, TEM and photoluminescence measurements can be found in Figure S1-S4.

\subsection{Photocatalytic performance}

When irradiating ZnO materials with light with photon energy larger than the band gap of $\mathrm{ZnO}$, electron-hole pairs will be generated, and the unpaired holes react with water to form hydroxyl radicals, which is a strong oxidizers and can degrade organic dyes into simple organics and finally into carbon dioxide. ${ }^{[25]}$ This process has been widely studied for the purpose of decontamination and purification of polluted water. Many strategies have been proposed to increase the photocatalytic degradation efficiency, e.g. by modifying the morphology, ${ }^{[9,26]}$ introducing dopants, ${ }^{[27,28]}$ integrating $\mathrm{ZnO}$ with other substrates, ${ }^{[29,30]}$ etc. 
Here we demonstrate that the $\mathrm{ZnO} \mathrm{NWs} / 3 \mathrm{D}$ silicon microstructures possess high photocatalytic activities towards the degradation of organic dye RhB.

For comparison, three different samples were prepared using different silicon substrates, including 3D silicon with large $2 \mu \mathrm{m}$ beam size (ZnO NWs/3D Si-L), 3D silicon with smaller $1 \mu \mathrm{m}$ beam size (ZnO NWs/3D Si-S), and planar silicon (ZnO NWs/2D Si). The typical morphology of the three samples are shown in Figure 3a-c. Figure 3d shows a series of UVvis absorption spectra of the aqueous solution of RhB with ZnO NWs/3D Si-L as the photocatalyst exposed to UV light for different times. The characteristic absorption peak of RhB dye centered at $554 \mathrm{~nm}$ decreases rapidly with increasing exposure time. Figure 3e shows the comparison of the photocatalytic activity of the three samples under the same experimental conditions. The blank experiment without the addition of photocatalyst shows almost no degradation of RhB under UV light illumination. While with the presence of different photocatalysts, the degradation of $\mathrm{RhB}$ is observed. The degradation of RhB follows the order of ZnO NWs/3D Si-L > ZnO NWs/3D Si-S > ZnO NWs/2D Si. Figure 3f shows the linear relationship between $\ln \left(\mathrm{C}_{t} / \mathrm{C}_{0}\right)$ and illumination time t, indicating the photocatalytic reaction follows first-order kinetics, $\ln \left(\mathrm{C}_{t} / \mathrm{C}_{0}\right)=-k t$, here $\mathrm{C}_{0}$ and $\mathrm{C}_{t}$ are the initial concentration and the concentration at reaction time $t$ of the RhB solution, respectively, and the slope $\mathrm{k}$ is the apparent reaction rate. The calculated rate constant for $\mathrm{ZnO}$ NWs/3D Si-L is $0.047 \mathrm{~min}^{-1}$, which is 1.5 times faster than $\mathrm{ZnO} \mathrm{NWs} / 3 \mathrm{D}$ Si-S $\left(0.031 \mathrm{~min}^{-1}\right)$, and 8 times faster than $\mathrm{ZnO} \mathrm{NWs} / 2 \mathrm{D} \mathrm{Si}\left(0.006 \mathrm{~min}^{-1}\right)$. The results confirm that the ZnO NWs/3D Si-L sample is superior in degrading RhB dye, and a comparison between ZnO NWs/3D Si-L and other hybrid structures reported in other studies can be seen in Table S1. The enhancement of photodegradation efficiency is attributed to the significant increase of $\mathrm{ZnO}$ NWs density, thus more photocatalytic reactions can take place in the same unit area. Figure S5 shows the relation between photodegradation rate $\mathrm{k}$ and the number density of $\mathrm{ZnO} \mathrm{NWs}$. To test the stability of the photocatalytic performance, ZnO NWs/3D Si-L was rinsed after each 
photocatalytic process and a new process was repeated afterwards, and the same degradation rate could be observed for 3 processes as shown in Figure 3g. This demonstrates the good reusability of ZnO NWs/3D Si microstructures for photocatalytic applications.

\subsection{Photocurrent generation}

The semiconductor nature of $\mathrm{ZnO}$ material makes it a favorable material for photosensitive devices, e.g. photovoltaics and solar cells. ${ }^{[31]}$ To improve the efficiency of the free charge migration, conductive substrates such as graphene are used to form into heterostructures with ZnO. ${ }^{[32,33]}$ This strategy, however, increases the economic cost for the fabrication process, thus hinders the large scale applications. Here we demonstrate that a significant enhancement of photocurrent response can be achieved by integrating ZnO NWs with the 3D silicon microstructures.

The photoresponse performances of ZnO NWs/3D Si -L, ZnO NWs/2D Si, and ZnO film/2D Si were investigated by running the line sweep voltammograms (LSV) with and without UV light irradiation ( $\lambda \sim 365 \mathrm{~nm}$ ) and an electrolyte, under ambient conditions). The bias potential was ranging from -0.5 to $+1.0 \mathrm{~V}$ vs. saturated calomel electrode (SCE). As shown in Figure 4a, ZnO NWs/2D Si and ZnO film/2D Si show negligible current in the dark. When illuminated with UV light, the two samples exhibit non-zero current densities. For ZnO NWs/3D Si sample, it is interesting to find that an obvious current is generated even without UV light illumination. A prominent photocurrent response can be observed with the UV irradiation. Specifically, a current density of $\sim 0.18 \mathrm{~mA} / \mathrm{cm}^{2}$ can be achieved at a bias of $1.0 \mathrm{~V}$, which is around one magnitude larger than the photocurrent density for $\mathrm{ZnO} \mathrm{NWs} / 2 \mathrm{D} \mathrm{Si}$ and $\mathrm{ZnO}$ film/2D Si, respectively. This photocurrent enhancement is related to the high density of ZnO NWs and more free charge carriers generated in a unit area, and the relationship between photocurrent amplitude at a bias of $0.5 \mathrm{~V}$ vs. SCE and the density of ZnO NWs is shown in

Figure S6. The amperometric I-t curves with the chopped illumination at the bias potential of $0.5 \mathrm{~V}$ vs. SCE were measured for the three samples as shown in Figure 5b. A photoresponse 
with a stable photocurrent for all the samples was observed. The current returned to the original values immediately as the light was switched off. Figure 5c compares the photocurrent density at the bias of $0.5 \mathrm{~V}$ vs. SCE for the different samples. The results of bare silicon and ZnO NWs/3D Si (beam size of $1 \mu \mathrm{m}$ ) are also shown for comparison. It can be seen that ZnO NWs/3D Si-L (beam size of $2 \mu \mathrm{m}$ ) gives a higher current density compared with $\mathrm{ZnO}$ NWs/3D Si-S (beam size of $1 \mu \mathrm{m}$ ), both are significantly higher than ZnO NWs/2D $\mathrm{Si}, \mathrm{ZnO}$ film/2D Si, and bare Si. The remarkable improvement of photocurrent response demonstrates the $\mathrm{ZnO} \mathrm{NWs} / 3 \mathrm{D}$ silicon microstructures as efficient alternative structures for photoelectric applications. It should be mentioned that by increasing the number of isolated layers, the photocatalytic and photocurrent performance could also be improved, however, this is limited by the fabrication process, thus a maximum number of 15 layers can be achieved and the highest photodegradation rate and photocurrent density are limited.

\subsection{Beyond ZnO - other materials}

$\mathrm{ZnO}$ is a versatile material that can be conveniently transformed into other functional materials, e.g. ZnS and ZIF-8 structures, which show a broader range of applications. By using a simple hydrothermal or solvothermal reaction, the present $\mathrm{ZnO} \mathrm{NWs} / 3 \mathrm{D}$ silicon microstructures can be converted into ZnS NWs/3D silicon and ZnO@ZIF-8 NWs/3D silicon microstructures, while the original 3D morphology can still be preserved.

$\mathrm{ZnS}$ is a typical semiconductor with a bandgap of $3.67 \mathrm{eV}$, and has been for photoelectric, ${ }^{[34]}$ and photovoltaics ${ }^{[35]}$ applications. A hydrothermal growth process was performed to convert ZnO NWs to ZnS nanostructures, during which a nanoscale Kirkendall effect happens inducing the formation of hollow structures. ${ }^{[36,37]}$ In Figure 5a, we can see that the structures remain intact after hydrothermal reactions, with "tubular” nanostructures covering the whole 3D substrate. From an enlarged view of one microbeam, the tube-like morphology can be distinguished (see the yellow square area in Figure 5b), and the hollow structure can also be confirmed by additional TEM and HAADF-STEM images as shown in 
Figure S7. The rough surface of the ZnS NWs indicates the converted sample is polycrystalline (Figure 5c), which is further confirmed by the selected area electron diffraction pattern (Figure 5d inset). The diffraction rings can be identified and indexed to (111), (311) and (220) planes of zinc-blend ZnS. Figure 5d shows a typical high-resolution TEM (HRTEM) image, and the lattice spacing was calculated to be $0.32 \mathrm{~nm}$, which corresponds to the (111) crystalline plane of a cubic ZnS crystal. HAADF-STEM image and elemental mapping results show a uniform distribution of $\mathrm{Zn}$ and S over the Si microbeam. The observation of some weak $\mathrm{O}$ signals suggests the coexistence of $\mathrm{ZnO}$ residues.

The other converted material is ZIF-8, which is a typical metal-organic framework (MOF) with a porous 3D zeolite crystal structure. ZIF-8 has been studied extensively and shows a great potential in catalysis, ${ }^{[38]}$ gas adsorption, ${ }^{[39]}$ and optics. ${ }^{[40,41]}$ Herein, solvothermal reaction was employed to convert the ZnO NWs into ZIF-8 structures on the 3D Si substrate. Figure 6a-c shows the SEM images of the transformed structures. It can be seen that ZIF-8 crystals cover the 3D silicon structures in a uniform manner. An enlarged view implies that there are still underlying ZnO NWs remaining on silicon substrates, and the ZIF-8 crystals filled the gaps between ZnO NWs. This is expected as each Zn atom from the the ZnO gives a 102 times larger ZIF-8 unit cell (4913 $\left.\AA^{3}\right)$ than the $\mathrm{ZnO}$ unit cell (48 $\left.\AA^{3}\right)$. HAADF-STEM (Figure 5d, Figure S8) and TEM images (Figure 5e,f) also show the porous morphology of ZIF-8 crystals, and residual ZnO NWs exist in the core of ZIF NWs, thus forming ZnO@ZIF-8 NWs/3D silicon microstructures. EDX element mapping on a section of ZnO@ZIF-8 NWs/3D silicon microstructures confirms the existence of N, O and C elements and verifies the formation of ZIF-8 structures on the surface of ZnO NWs (Figure 5g). Compared with the traditional powder-like ZIF-8 crystals, the obtained ZIF-8 NWs /3D silicon microstructures can serve as a reusable and mechanically robust substrate. Meanwhile, the spatial density of ZIF-8 NWs can also be modulated on the 3D structure geometry. 
Therefore, an improved performance can be expected for applications as catalysis and gas adsorption. Further studies on the applications of these 3D nanostructures are in progress.

\section{Conclusions}

In summary, a novel highly ordered 3D silicon micro-mesh structure is presented as a robust substrate to significantly increase the surface area of different materials. By integrating $\mathrm{ZnO}$ NWs with the 3D silicon substrates, both photocatalytic and photocurrent generation performances were improved in a large scale compared with 2D plane substrate grown ZnO NWs. The fabricated ZnO NWs can also be converted to other functional materials including ZnS and ZIF-8, while the ordered structure and morphology remain intact, showing the flexibility and potential of 3D structures for other applications. The whole fabrication process is easy to control and less time consuming compared with traditional multiple-time growth method. Since the 3D silicon substrate was fabricated with standard techniques in semiconductor industries, it is promising to integrate the funtionalities of different NW structures onto 3D silicon substrates with micro-electro-mechanical and chemical system designs, to optimize yields in complicated range of applications especially for on-chip applications.

\section{Experimental Section}

Fabrication of 3D silicon micro-mesh structures: Double side polished silicon wafer $(100 \mathrm{~mm}$, n-doped, 1-20 $\Omega \mathrm{cm}$ ) was used to fabricate 3D silicon micro-mesh structures. Patterns were defined with a direct exposure maskless lithography system (tabletop maskless aligner MLA100, Heidelberg), and a negative tone resist (AZ nLOF 2020, MicroChemicals) was used. Plasma etching was performed in a dual source etching system (DRIE Pegasus, SPTS). After 
etching, the samples were cleaved into pieces with size of $1.2 \mathrm{~cm}$ by $1.2 \mathrm{~cm}$, and cleaned with a plasma ashing system (PVA TePla 300).

$\mathrm{ZnO}$ coating and hydrothermal synthesis: The $\mathrm{ZnO}$ seed layer was deposited with a thermal ALD system (Picosun R200). Diethylzinc $\left(\mathrm{Zn}\left(\mathrm{C}_{2} \mathrm{H}_{5}\right)_{2}\right.$, DEZ) and deionized water were used as precursors, with $\mathrm{N}_{2}$ as carrier gas. The chamber temperature was set to be $200{ }^{\circ} \mathrm{C}$ and the deposition rate was around $0.15 \mathrm{~nm}$ per cycle. The ZnO NWs were then synthesized by a hydrothermal reaction. Typically, hexamethylenetetramine (HMTA, $0.1 \mathrm{~g}$ ) and zinc nitrate hexahydrate $\left(\mathrm{Zn}\left(\mathrm{NO}_{3}\right)_{2}, 0.22 \mathrm{~g}\right)$ were mixed and dissolved in $60 \mathrm{~mL}$ of de-ionized water (DIW). The mixture was then transferred into a Teflon-lined stainless-steel autoclave with $100 \mathrm{~mL}$ capacity. The 3D Si micro-mesh structures with ZnO seed layer were put upside down in the solutions, then the autoclave was sealed for solution reaction at $90{ }^{\circ} \mathrm{C}$ for $20 \mathrm{~h}$. After the autoclave cooled down to room temperature naturally, the samples were pick up by tweezers, washed with distilled water and dried in air.

Materials characterization: The thickness of ALD grown ZnO layer was measured by spectroscopic ellipsometry (Ellipsometer VASE, J. A. Woolam). PL spectra were measured with a PL mapping system (Accent RPM 2000 series), with excitation wavelength at $404 \mathrm{~nm}$ and energy of $20 \mathrm{~mW}$. The morphology of the samples were characterized with scanning electron microscopy (SEM Supra 60VP, 3 keV, Zeiss), transmission electron microscopy (TEM, Tecnai G² T20, 200 keV, FEI) coupled with an EDS X-ray spectrometer (Oxford Instrument). Crystallographic information for the samples was collected using a Bruker Model D8 Advanced powder X-ray diffractometer (XRD) with Cr Ka irradiation (2.08 Å). Transmission electron microscopy (TEM), high resolution transmission electron microscopy (HRTEM), high angle annular dark-field scanning transmission electron microscopy (HAADF-STEM), and energy dispersive X-ray spectroscopy mapping analysis were performed on Tecnai $\mathrm{G}^{2} \mathrm{~T} 20$ microscope (200 keV, FEI). 
Photocatalytic performance test: The photocatalytic activity of the sample was evaluated by the degradation of rhodamine $\mathrm{B}\left(\mathrm{RhB}, 1.0 \times 10^{-5} \mathrm{M}\right)$ aqueous solution under UV light (365 nm), using a $300 \mathrm{~W}$ Xe arc lamp (CEL-HXF 300) equipped with an UV cutoff filter as a light source. The samples were put into $100 \mathrm{~mL}$ of $\mathrm{RhB}$ solution. The aqueous solution was stirred in the dark for $1 \mathrm{~h}$ to reach a complete adsorption-desorption equilibrium. The reaction system was placed in a sealed black box with the top opened, and was maintained a distance of $15 \mathrm{~cm}$ from the light source. After initiation of the reaction by irradiation, a $5 \mathrm{~mL}$ sample of the suspension was taken out at regular intervals ( $20 \mathrm{~min})$. In order to measure the RhB degradation, UV-visible spectra of the solution was recorded by using UV-2550 UV-visible spectrophotometer (Shimadzu, Japan).

Photocurrent measurement: Standard three-electrode system, including Pt wire as counter electrode, saturated calomel electrode (SCE) as reference electrode, and $\mathrm{ZnO} / \mathrm{Si}$ samples as working electrodes, was used throughout the measurements. Aqueous solution of $\mathrm{Na}_{2} \mathrm{SO}_{4}(0.5 \mathrm{M}, \mathrm{pH}=7.0)$ was prepared as the electrolyte. The working electrodes with half area of the sample were dipped into the electrolyte, and irradiated from the front side under a UV light $(\lambda \sim 365 \mathrm{~nm})$. The distance from the light source to sample was around $10 \mathrm{~cm}$. The linear sweep voltammetry (LSV; I-V) curves with a scan rate of $5 \mathrm{mV} \mathrm{s}^{-1}$ at the bias potential (vs. SCE) range from -0.5 to $+1.0 \mathrm{~V}$ and the amperometric I-t curves with the chopped illumination at the bias potential of $0.5 \mathrm{~V}$ vs. SCE were measured for the different working electrodes to compare their photocurrent outputs and photoresponse switching behavior. All the measurements were performed at room temperature.

Conversion to $\mathrm{ZnS}$ : ZnO NWs were converted to $\mathrm{ZnS}$ by a hydrothermal reaction. In a typical process, ZnO/Si samples were put into a Teflon lined autoclave (100 mL capacity) containing $50 \mathrm{~mL}$ of thioacetamide (TAA, 0.2M, Sigma-Aldrich), and then kept at $120^{\circ} \mathrm{C}$ for 10 hours. After that, the samples were washed with distilled water and dried in air. The TAA amount was estimated to be sufficient for a maximum conversion of $\mathrm{ZnO}$ nanowires. 
Conversion to ZIF-8 structures: The ZnO NWs were converted into ZIF-8 structures by a solvothermal reaction. Typically, dimethylformamide (45 mL) was mixed with 2methylimidazole $(0.2 \mathrm{~g})$ and deionized water $(15 \mathrm{~mL})$ in a Teflon lined autoclave with 100 mL capacity, ZnO/Si samples were put into the container, sealed, and placed inside a convection oven for $20 \mathrm{~h}$ at $75^{\circ} \mathrm{C}$. After the reaction, the samples were rinsed with deionized water several times and dried in air.

\section{Supporting Information}

Supporting Information is available from the Wiley Online Library or from the author.

\section{Acknowledgements}

The Supporting Information is available free of charge on the ACS Publications website

\section{Conflict of Interest}

The authors declare no conflict of interest.

Received: ((will be filled in by the editorial staff))

Revised: ((will be filled in by the editorial staff)) Published online: ((will be filled in by the editorial staff))

\section{References}

[1] S. Matthias, F. Müller, C. Jamois, R. B. Wehrspohn, U. Gösel, Adv. Mater. 2006, 16, 2166.

[2] B. H. Lee, J. Hur, M. H. Kang, T. Bang, D. C. Ahn, D. Lee, K. H. Kim, Y. K. Choi, Nano Lett. 2016, 16, 1840.

[3] A. Du Pasquier, H. Chen, Y. Lu, Appl. Phys. Lett. 2006, 89, 253513.

[4] J. Yu, X. Yu, Environ. Sci. Technol. 2008, 42, 4902.

[5] S. K. Sami, S. Siddiqui, S. Shrivastava, N. E. Lee, C. H. Chung, Small 2017, 13, 46.

[6] Z. L. Wang, J. Song, Science 2006, 312, 242.

[7] X. Li, M. Chen, R. Yu, T. Zhang, D. Song, R. Liang, Q. Zhang, S. Cheng, L. Dong, A.

Pan, Z. L. Wang, J. Zhu, C. Pan, Adv. Mater. 2015, 27, 4447.

[8] Z. L. Wang, J. Phys. Condens. Matter. 2004, 16, R829. 
[9] H. Sun, Y. Yu, J. Luo, M. Ahmad, J. Zhu, CrystEngComm 2012, 14, 8626.

[10] X. Wang, M. Ahmad, H. Sun, Materials 2017, 10, 1304.

[11] Y. K. Mishra, R. Adelung, Mater. Today 2017, DOI: 10.1016/j.mattod.2017.11.003.

[12] Q. Wan, Q. H. Li, Y. J. Chen, T. H. Wang, X. L. He, J. P. Li, C. L. Lin, Appl. Phys. Lett. 2004, 84, 3654.

[13] C. J. Lee, T. J. Lee, S. C. Lyu, Y. Zhang, H. Ruh, H. J. Lee, Appl. Phys. Lett. 2002, 81, 3648.

[14] S. H. Ko, D. Lee, H. W. Kang, K. H. Nam, J. Y. Yeo, S. J. Hong, C. P. Grigoropoulos, H. J. Sung, Nano Lett. 2011, 11, 666.

[15] R. Cai, J. G. Wu, L. Sun, Y. J. Liu, T. Fang, S. Zhu, S. Li, Y. Wang, L. Guo, C. Zhao, A. Wie, Mater. Des. 2016, 90, 839.

[16] D. Shao, J. Gao, G. Xin, Y. Wang, L. Li, J. Shi, J. Lian, N. Koratkar, S. Sawyer, Small 2015, 11, 4785.

[17] X. Chen, L. Liu, Y. Feng, L. Wang, Z. Bian, H. Li, Z. L. Wang, Mater. Today. 2017, 20, 501.

[18] A. Kargar, K. Sun, Y. Jing, C. Choi, H. Jeong, G. Y. Jung, S. Jin, D. Wang, ACS Nano 2013, 7, 9407.

[19] K. Mølhave, B. A. Wacaser, D. H. Petersen, J. B. Wagner, L. Samuelson, P. Bøggild, Small 2008, 4, 1741.

[20] B. Chang, P. Leussink, F. Jensen, J. Hübner, H. Jansen, Microelectron. Eng. 2018, 191, 77.

[21] B. Chang, F. Jensen, J. Hübner, H. Jansen, J. Micromech. Microeng. 2018, 28, 10.

[22] E. Shkondin, O. Takayama, M. A. Panah, P. Liu, P. V. Larsen, M. D. Mar, F. Jensen, A. V. Lavrinenko, Opt. Mater. Express. 2017, 7, 1606.

[23] L. E. Greene, M. Law, J. Goldberger, F. Kim, J. C. Johnson, Y. Zhang, R. J. Saykally, P. Yang, Angew. Chem. Int. Ed. 2003, 42, 3031. 
[24] C. L. Hsu, S. J. Chang, Small 2014, 10, 4562.

[25] K. M. Lee, C. W. Lai, K. S. Ngai, J. C. Juan, Water. Res. 2016, 88, 428.

[26] D. Li, H. Haneda, Chemosphere 2003, 51, 129.

[27] V. C. Srivastava, Ind. Eng. Chem. Res. 2013, 52, 17790.

[28] Ö. A. Yıldırım, H. E. Unalan, C. Durucan, J. Am. Ceram. Soc. 2013, 96, 766.

[29] K. Dai, G. Dawson, S. Yang, Z. Chen, L. Lu, Chem. Eng. J. 2012, 191, 571.

[30] H.N. Tien, N. T. Khoa, S. H. Hahn, J. S. Chung, E. W. Shin, S. H. Hur, Chem. Eng. J. 2013, 229, 126.

[31] P. H. Rekemeyer, S. Chang, C. H. M. Chuang, G. W. Hwang, M. G. Bawendi, S. Gradečak, Adv. Energy Mater. 2016, 6, 24.

[32] X. Men, H. Chen, K. Chang, X. Fang, C. Wu, W. Qin, S. Yin, Appl. Catal. B 2016, 187, 367.

[33] S. Yin, X. Men, H. Sun, P. She, W. Zhang, C. Wu. W.Qin, X. Chen, J. Mater. Chem. A 2015, 3, 12016.

[34] W. Tian, C. Zhang, T. Zhai, S. L. Li, X. Wang, J. Liu, X. Jie, D. Liu, M. Liao, Y. Koide, D. Golberg, Y. Bando, Adv. Mater. 2014, 26, 3088.

[35] S. M. Kobosko, D. H. Jara, P. V. Kamat, ACS Appl. Mater. Interfaces 2017, 9, 33379.

[36] H. J. Fan, U. Gösele, M. Zacharias, Small 2007, 3, 1660.

[37] H. Sun, Y. Chen, X. Wang, Y. Xie, W. Li, X. Zhang, J. Nanoparticle Res. 2011, 13, 97.

[38] Y. Qian, T. An, K. E. Birgersson, Z. Liu, D. Zhao, Small 2018, 14, 1704169.

[39] C. L. Hobday, C. H. Woodall, M. J. Lennox, M. Frost, K. Kamenev, T. Düren, C. A. Morrison, S. A. Moggach, Nat. Commun. 2018, 9, 1429.

[40] S. van Cleuvenbergen, I. Stassen, E. Gobechiya, Y. Zhang, K. Markey, D. E. De Vos, C. Kirschhock, B. Champagne, T. Verbiest, M. A. van der Veen, Chem. Mater. 2016, 28, 3203. [41] B. Chang, Y. Yang, H. Jansen, F. Ding, K. Mølhave, H. Sun, Adv. Mater. Interfaces 2018, 5, 1701270. 

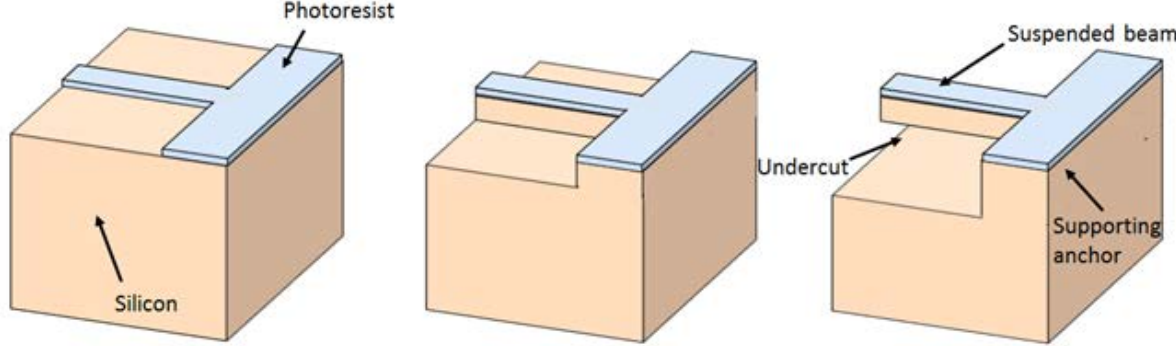

(4) Repeat (2) and (3) for 3 times

(5) Plasma ashing \& ALD

(6) Hydrothermal reaction
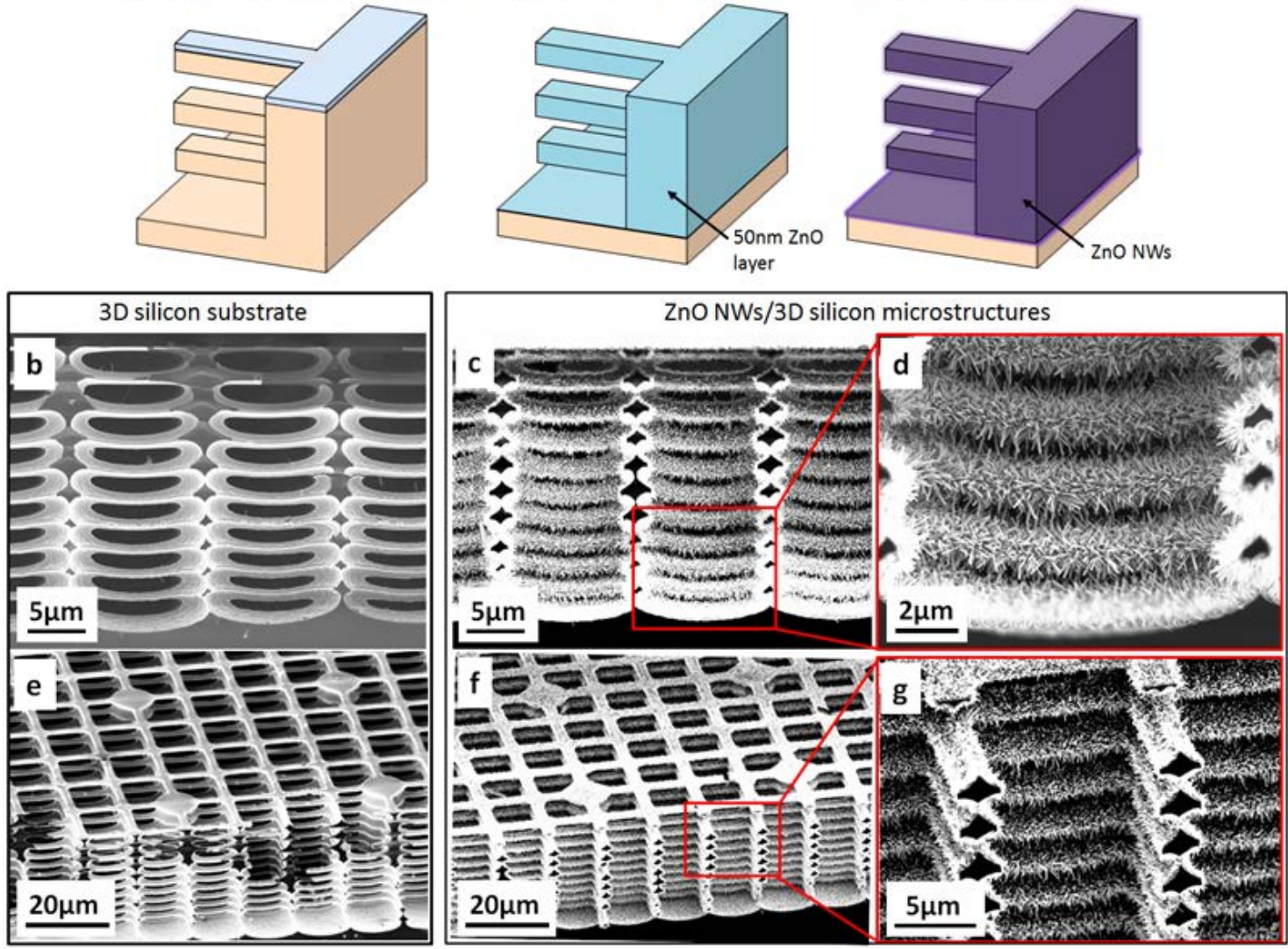

Figure 1. (a) Process flow to fabricate ZnO NWs/3D silicon structures: (1) UV lithography; (2) first DREM cycle to create structures; (3) first isotropic etch to create suspended structures; (4) repeat DREM cycles followed by isotropic etch for 3 times; (5) plasma ashing to clean the polymers and deposit $\mathrm{ZnO}$ with ALD; (6) hydrothermal reaction to grow ZnO 
NWs; SEM images of 3D silicon substrate in (b) cross section view and (e) tilted view. SEM images of $\mathrm{ZnO} \mathrm{NWs} / 3 \mathrm{D}$ silicon structures in (c, d) cross section view and (f, g) tilted view.
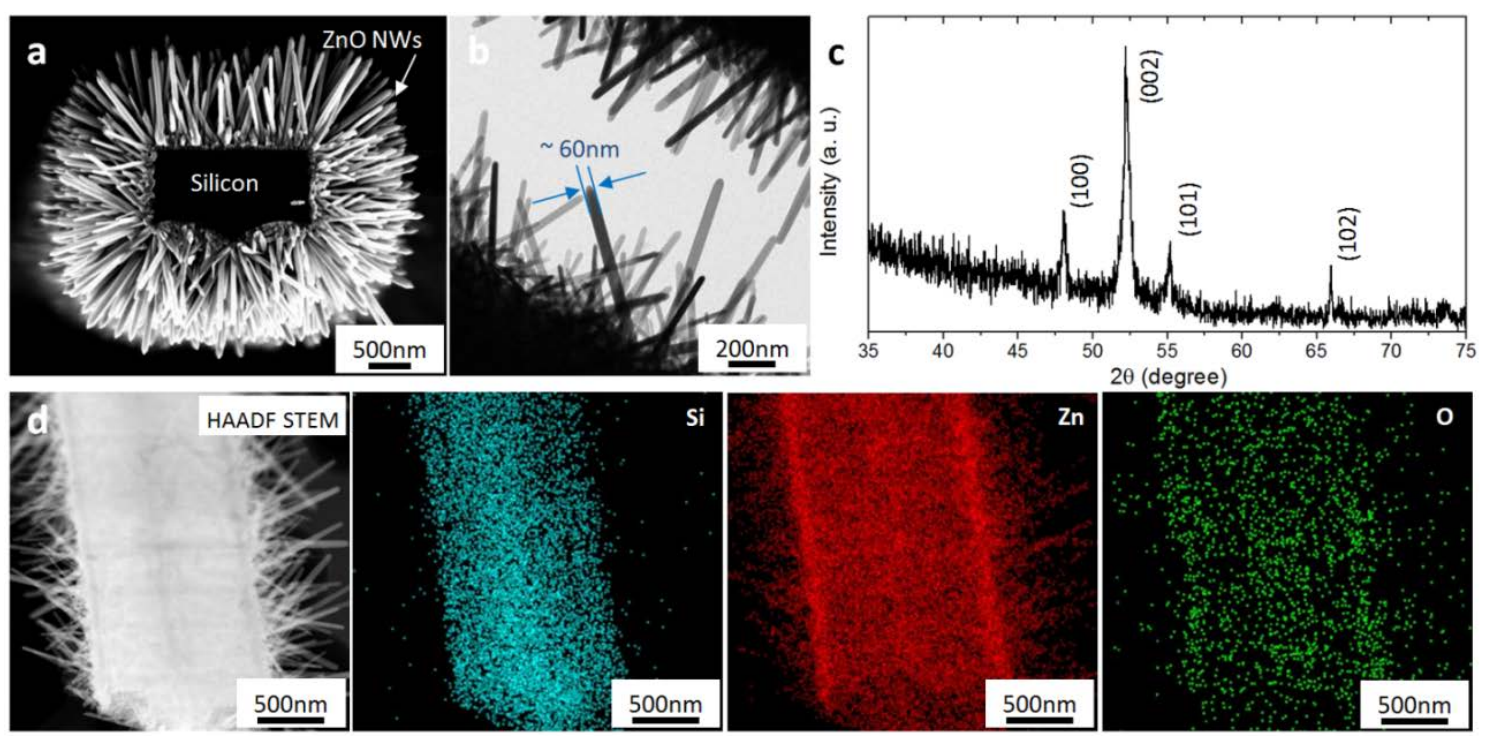

Figure 2. (a) SEM image of silicon microbeam covered with ZnO NWs; (b) TEM image of ZnO NWs; (c) XRD pattern of ZnO NWs/3D silicon structures; (d) HAADF-STEM image and element mapping of a silicon microbeam covered with ZnO NWs. 

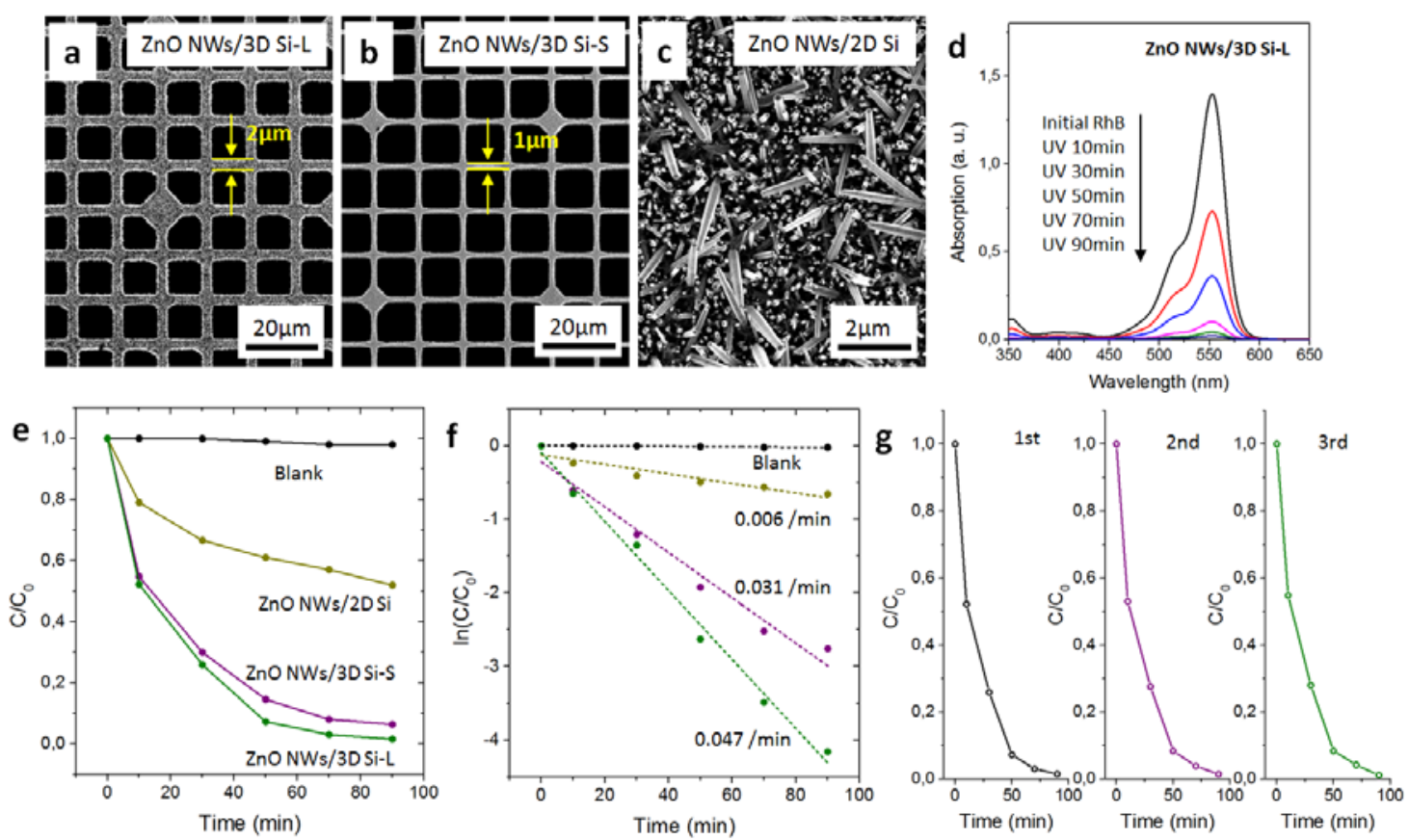

Figure 3. Photocatalytic performance of ZnO NWs/3D silicon structures. (a-c) SEM images (top view) of ZnO NWs/3D Si-L, ZnO NWs/3D Si-S, and ZnO NWs/2D Si; (d) Time dependent UV-visible spectra of RhB solutions with presence of NWs/3D Si-L; (e), (f) Degradation curves for different photocatalysts under UV light illumination; (g) Time profile of the change in concentration of RhB aqueous solution for the first three cycles in the presence of $\mathrm{ZnO} \mathrm{NWs} / 3 \mathrm{D}$ Si-L. 

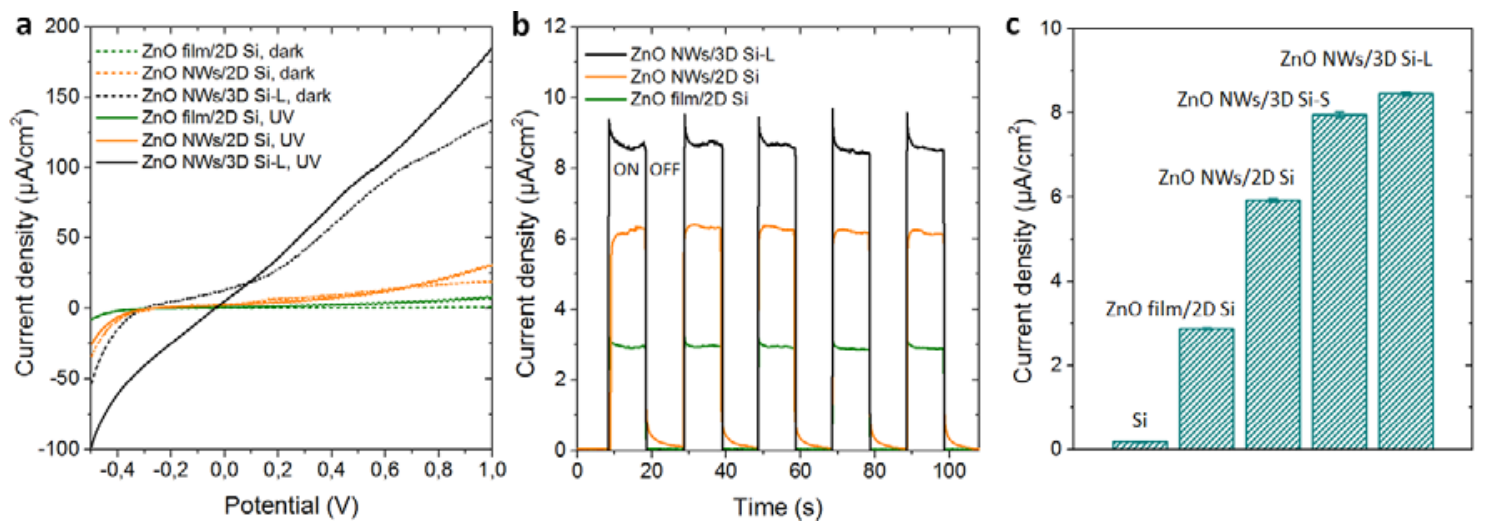

Figure 4. (a) Line sweep voltammograms; (b) photocurrent responses with UV light five on/off cycles at a bias of $0.5 \mathrm{~V}$ vs. SCE; (c) average photocurrents for different samples at a bias of $0.5 \mathrm{~V}$ vs. SCE. 

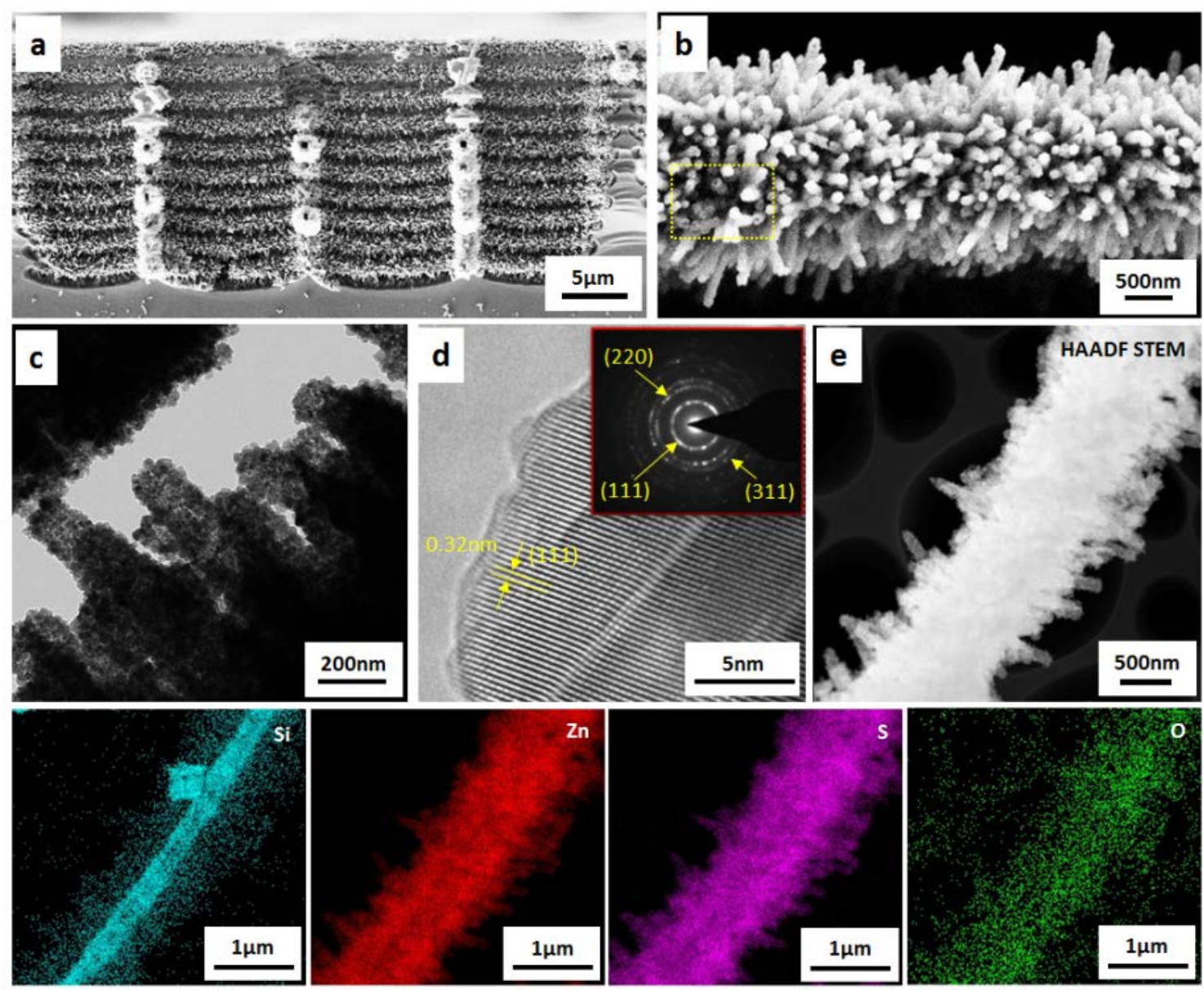

Figure 5. (a, b) SEM, (c) TEM, and (d) HRTEM of ZnS NWs/3D silicon microstructures. The inset shows the SAED pattern. (e) HAADF-STEM images and corresponding EDX element mapping. 


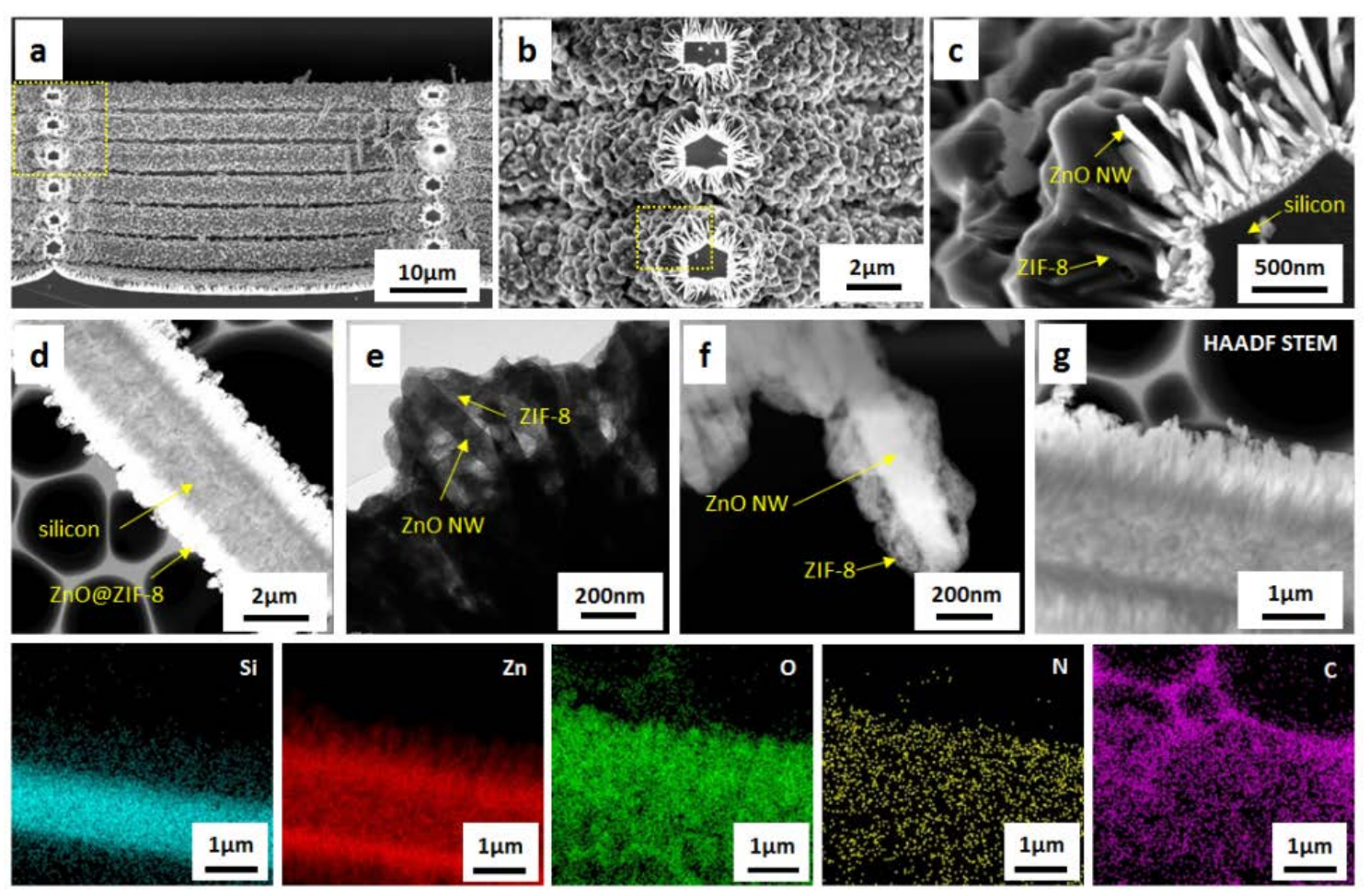

Figure 6. (a-c) SEM, (d) HAADF-STEM, and (e, f) TEM images of ZnO@ZIF-8 NWs/3D silicon microstructures; (g) HAADF STEM image and corresponding EDX element mapping results of the ZnO@ZIF-8 NWs/3D silicon microstructures. 
Highly ordered 3D silicon micro-mesh structures are used as a substrate for growth of different nanowire arrays, the density of nanowires is increased by one magnitude compared to the 2D substrates, which gives a significant improvement of photodegradation efficiency and photocurrent generation.

Keywords: three dimensional structures; nanowire arrays; photocatalytic; photocurrent; materials conversion

Bingdong Chang *, Yingying Tang, Mingli Liang, Henri Jansen, Flemming Jensen, Bo Wang, Kristian Mølhave, Jörg Hübner and Hongyu Sun *

Highly Ordered 3D Silicon Micro-Mesh Structures Integrated with Nanowire Arrays: A Multifunctional Platform for Photodegradation, Photocurrent Generation, and Materials Conversion

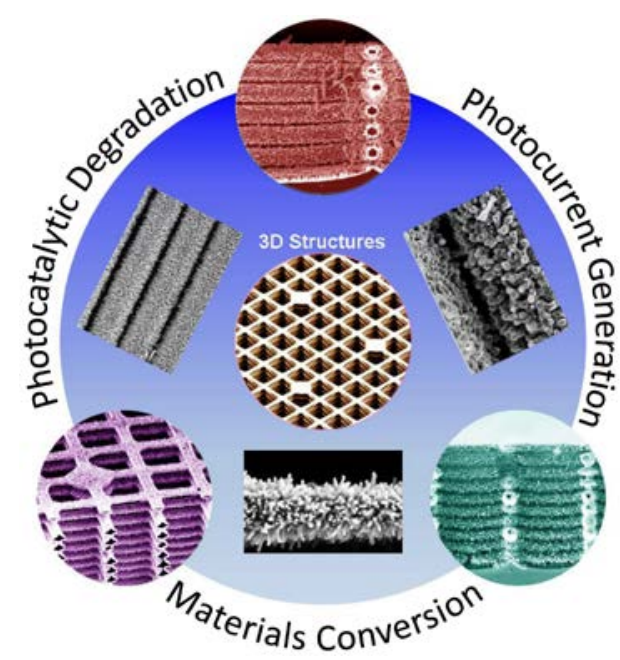




\section{Supporting Information}

Highly Ordered 3D Silicon Micro-Mesh Structures Integrated with Nanowire Arrays: A Multifunctional Platform for Photodegradation, Photocurrent Generation, and Materials Conversion

Bingdong Chang *, Yingying Tang, Mingli Liang, Henri Jansen, Flemming Jensen, Bo Wang, Kristian Mølhave, Jörg Hübner and Hongyu Sun * 


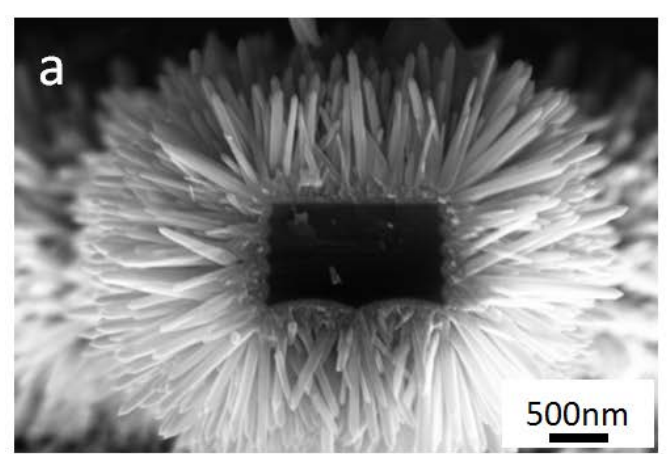

Si $K \alpha 1$
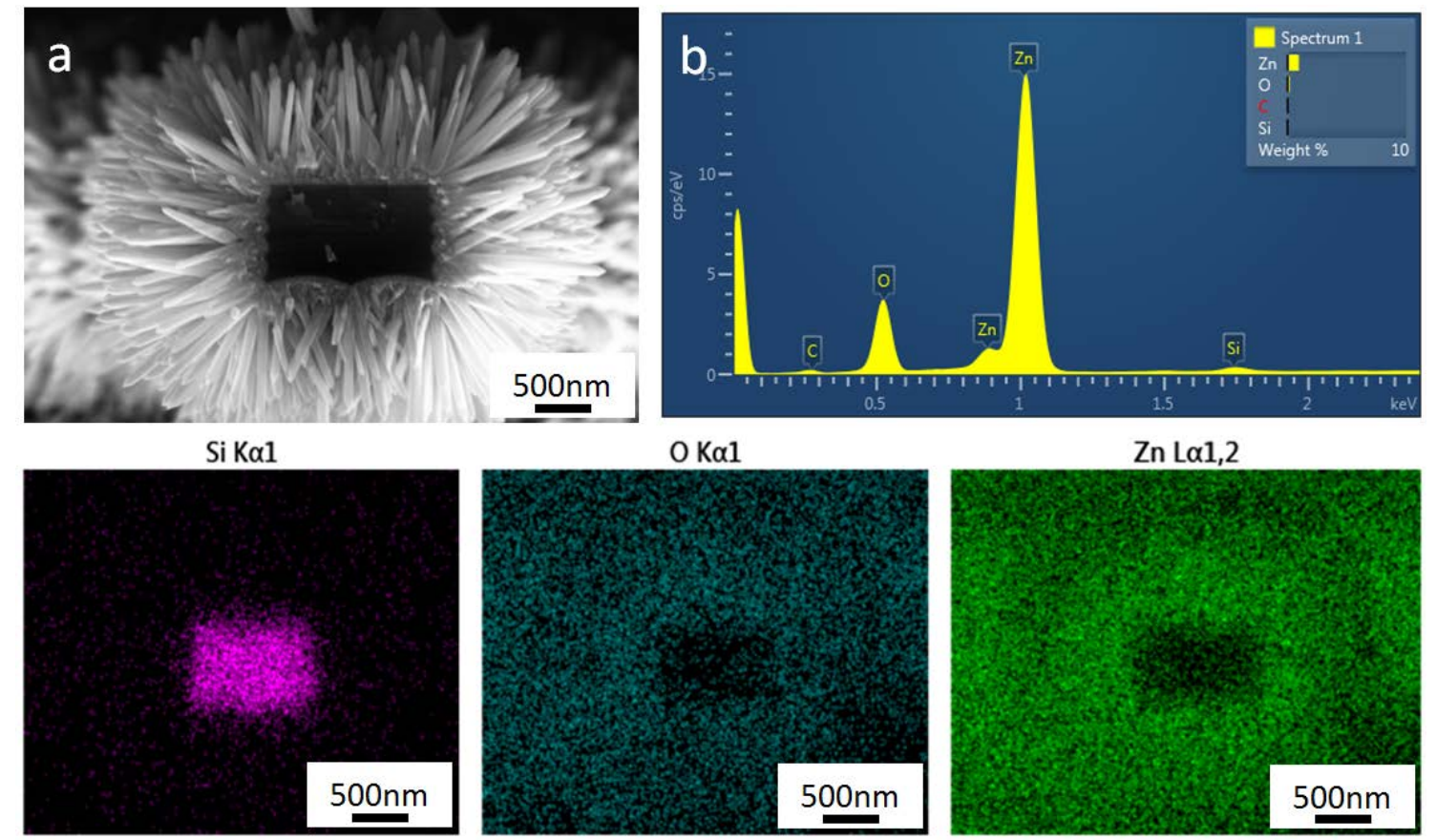

Zn L $\alpha 1,2$

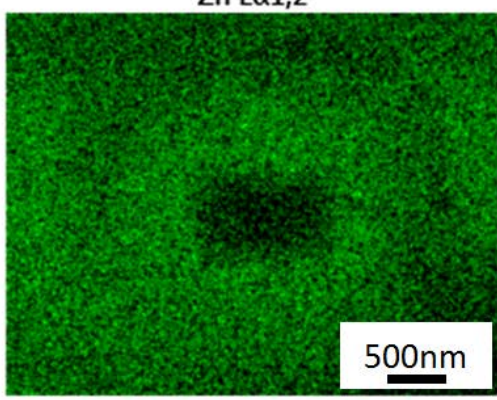

Figure S1. (a) SEM image of a suspended silicon microbeam covered by ZnO NWs; (b) EDX spectrum and element mapping of the structure, which shows the existence of $\mathrm{Si}, \mathrm{O}$, and $\mathrm{Zn}$ elements. 


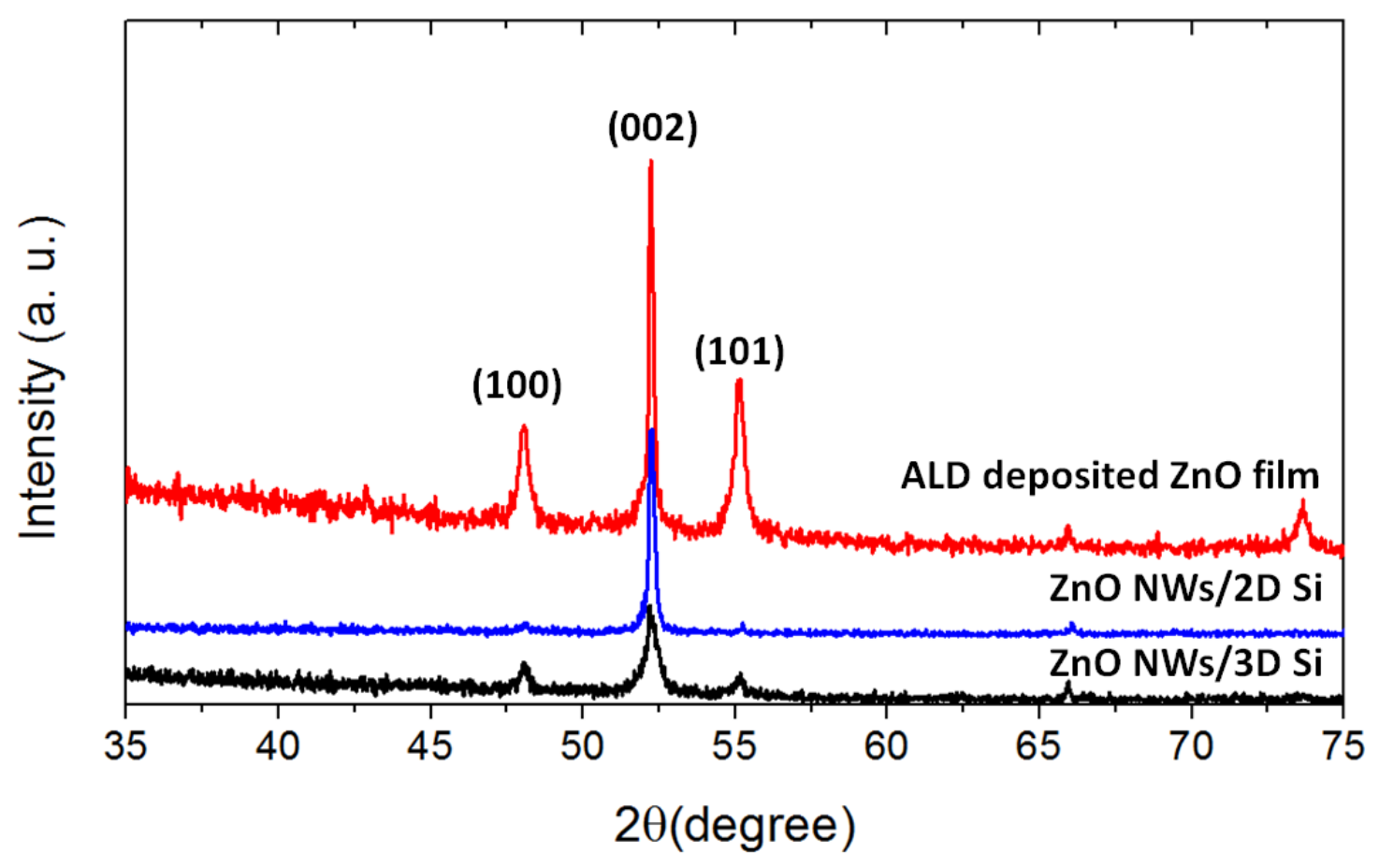

Figure S2. XRD patterns of three different samples. All samples show a significant (002) diffraction peak of wurtzite $\mathrm{ZnO}$ phase. Notice that $\mathrm{ZnO} \mathrm{NWs} / 2 \mathrm{D}$ Si gives a much stronger (002) diffraction intensity compared with $\mathrm{ZnO} \mathrm{NWs} / 3 \mathrm{D}$ Si, this might be due to the growth direction of ZnO NWs on a 2D silicon plane substrate is mostly upwards along (002) direction, while on a 3D surface, the growth of ZnO NWs follows the surface of 3D structures, thus giving the possibilities for growth in other crystalline orientations. 


\begin{tabular}{|c|c|c|c|c|c|c|}
\hline \# & Structures & $\begin{array}{l}\text { UV } \\
\text { irradiation } \\
\text { power }\end{array}$ & $\begin{array}{l}\text { Sample } \\
\text { size }\end{array}$ & $\begin{array}{l}\text { Time for RhB } \\
\text { concentration to be } \\
\text { reduced to below } \\
10 \%\end{array}$ & $\begin{array}{l}\text { Initial } \\
\text { concentration } \\
\text { of } \mathrm{RhB}\end{array}$ & Reference \\
\hline 1 & $\begin{array}{l}\text { ZnO NWs/3D } \\
\text { Si-L }\end{array}$ & $300 \mathrm{~W}$ & $\begin{array}{l}1.2 \mathrm{~cm} \times \\
1.2 \mathrm{~cm}\end{array}$ & $50 \mathrm{~min}$ & $\begin{array}{l}1 \times 10^{-5} \mathrm{M} \\
(4.79 \mathrm{mg} / \mathrm{L})\end{array}$ & This work \\
\hline 2 & $\begin{array}{l}\text { ZnO nanorod } \\
\text { arrays/3D Ni } \\
\text { foams }\end{array}$ & $100 \mathrm{~W}$ & $\begin{array}{l}3.5 \mathrm{~cm} \times \\
2.5 \mathrm{~cm}\end{array}$ & $90 \mathrm{~min}$ & $5 \mathrm{mg} / \mathrm{L}$ & [1] \\
\hline 3 & $\begin{array}{l}\text { Cl-doped } \mathrm{ZnO} \\
\text { NWs on 3D } \\
\text { graphene foams }\end{array}$ & $150 \mathrm{~W}$ & $\begin{array}{l}2 \mathrm{~cm} \times 2 \\
\mathrm{~cm}\end{array}$ & $62 \mathrm{~min}$ & $5 \mathrm{mg} / \mathrm{L}$ & [2] \\
\hline 4 & $\begin{array}{l}\mathrm{ZnO} \text { needle } \\
\text { flowers }\end{array}$ & $300 \mathrm{~W}$ & $\begin{array}{l}1 \mathrm{~cm} \times 1.2 \\
\mathrm{~cm}\end{array}$ & $55 \mathrm{~min}$ & $\begin{array}{l}1 \times 10^{-5} \mathrm{M} \\
(4.79 \mathrm{mg} / \mathrm{L})\end{array}$ & [3] \\
\hline 5 & $\begin{array}{l}\mathrm{MoS}_{2} \\
\text { nanosheets on } \\
\mathrm{TiO}_{2} \text { nanotube } \\
\text { arrays }\end{array}$ & $230 \mathrm{~W}$ & $1.766 \mathrm{~cm}^{2}$ & $>120 \mathrm{~min}$ & $10 \mathrm{mg} / \mathrm{L}$ & [4] \\
\hline
\end{tabular}

Table S1. A table to compare the photocatalytic performance of our structures (ZnO NWs/3D Si-L) with previous literatures. From the table, we can see that the ZnO NWs/3D Si structures have comparable photocatalytic efficiency with other hybrid structures reported before. [1] X. Chen, L. Liu, Y. Feng, L. Wang, Z. Bian, H. Li, Z. L. Wang, Mater. Today. 2017, 20, 501.

[2] D. Shao, J. Gao, G. Xin, Y. Wang, L. Li, J. Shi, J. Lian, N. Koratkar, S. Sawyer, Small 2015, 11, 4785.

[3] H. Sun, Y. Yu, J. Luo, M. Ahmad, J. Zhu, CrystEngComm 2012, 14, 8626.

[4] L. Zheng, S. Han, H. Liu, P. Yu, X. Fang. Small 2016, 12, 1527. 


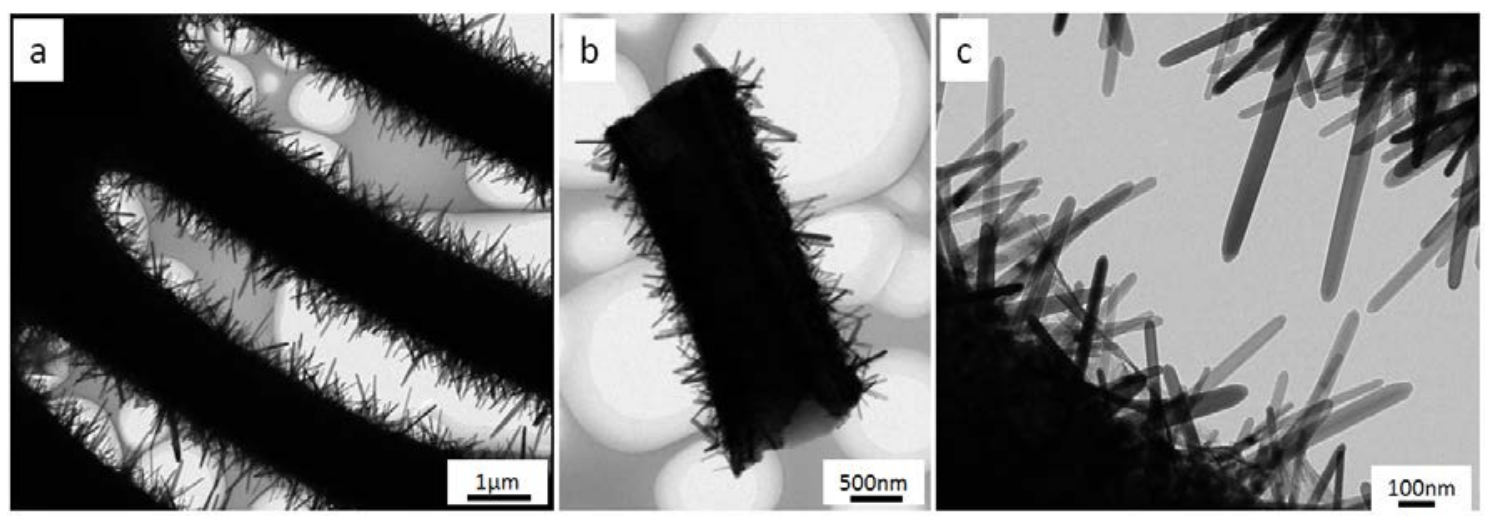

Figure S3. Typical TEM images of ZnO NWs/3D silicon structures. 

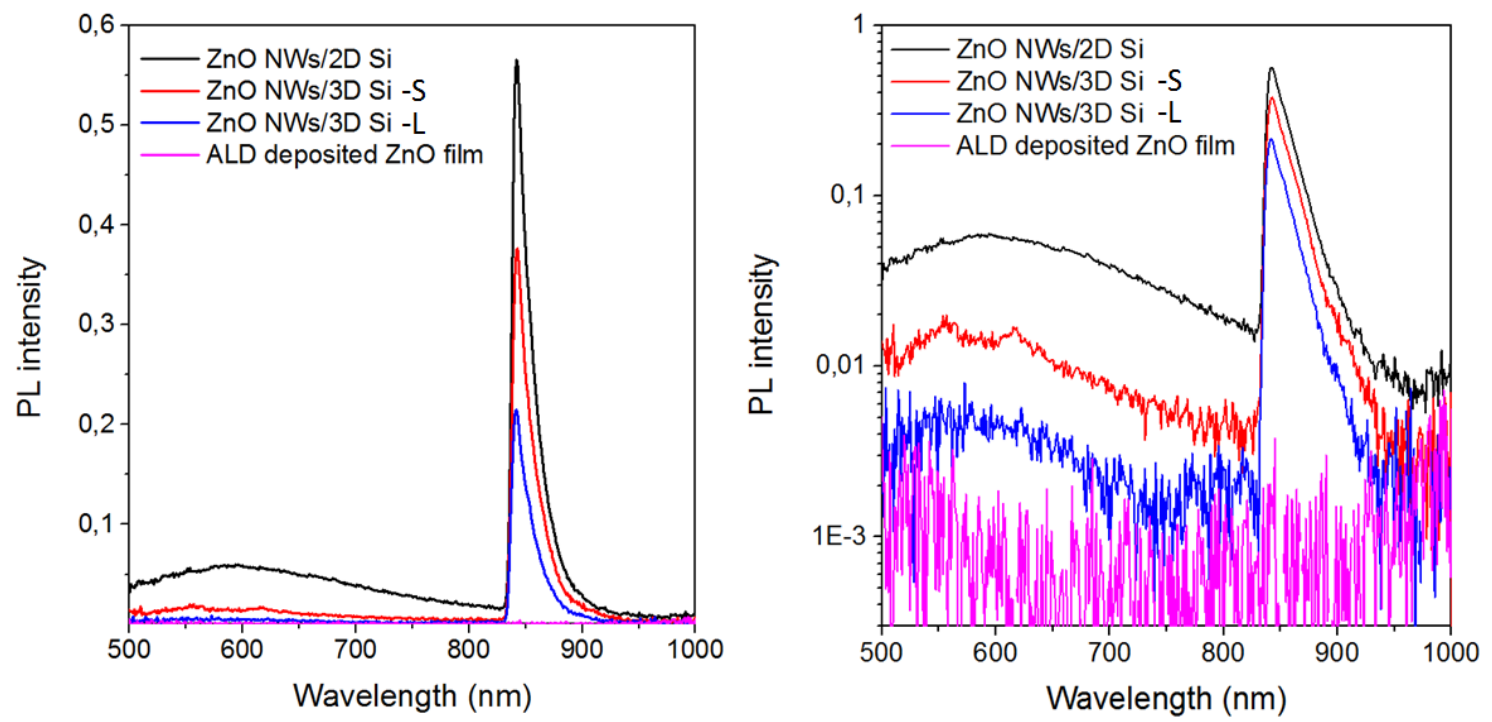

Figure S4. PL measurements for different samples. Due to the limitation of the laser source on the setup, near band edge (NBE) emission in UV region cannot be observed, while a defect related deep level emission (DLE) in visible region is obvious. The second order diffraction of NBE gives an emission peak at around $850 \mathrm{~nm}$, which is normally pronounced for $\mathrm{ZnO}$ nanocrystals with high crystalline quality. Compared with the PL spectra from ZnO NWs/2D $\mathrm{Si}, \mathrm{ZnO}$ NWs on 3D silicon structures give a smaller signal, which is due to the scattering decay of emitted light on the $\mathrm{ZnO}$ nanostructures. 


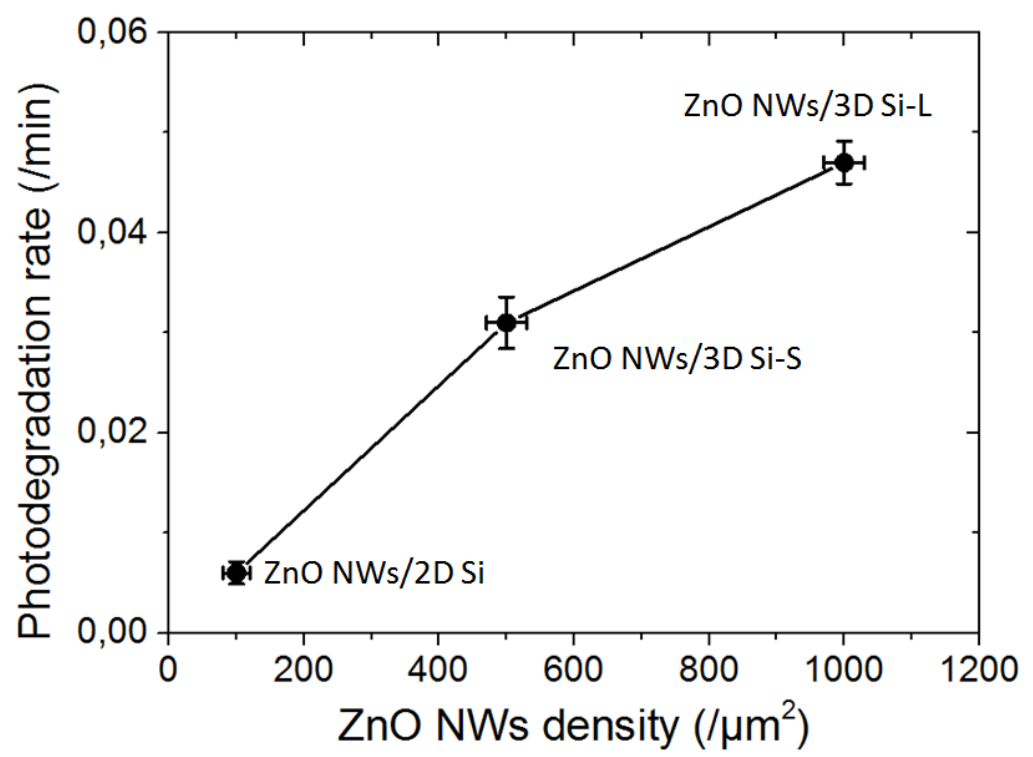

Figure S5. Relation between photodegradation rate k and the density of $\mathrm{ZnO}$ NWs. 


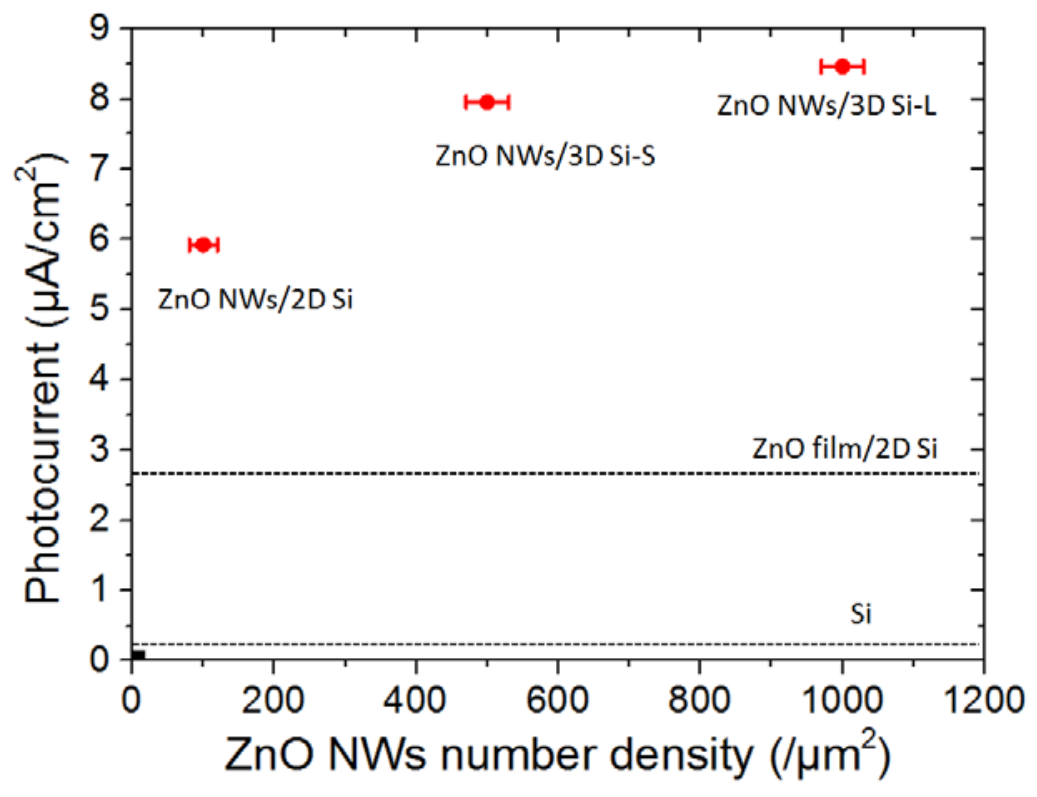

Figure S6. Relation between photocurrent amplitude at a bias of $0.5 \mathrm{~V}$ vs. SCE and the density of ZnO NWs. The photocurrent values for $\mathrm{ZnO}$ film/2D Si and bare Si are also shown for comparison. 


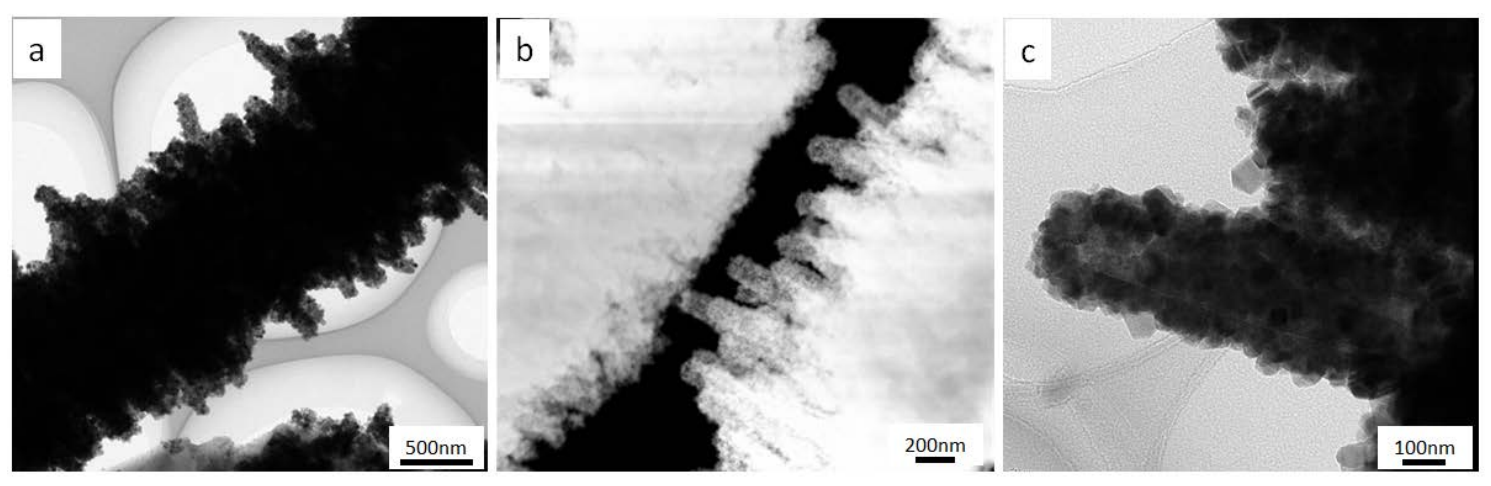

Figure S7. Typical (a, c) TEM and (b) HAADF-STEM images of ZnS NWs/3D silicon structures. 

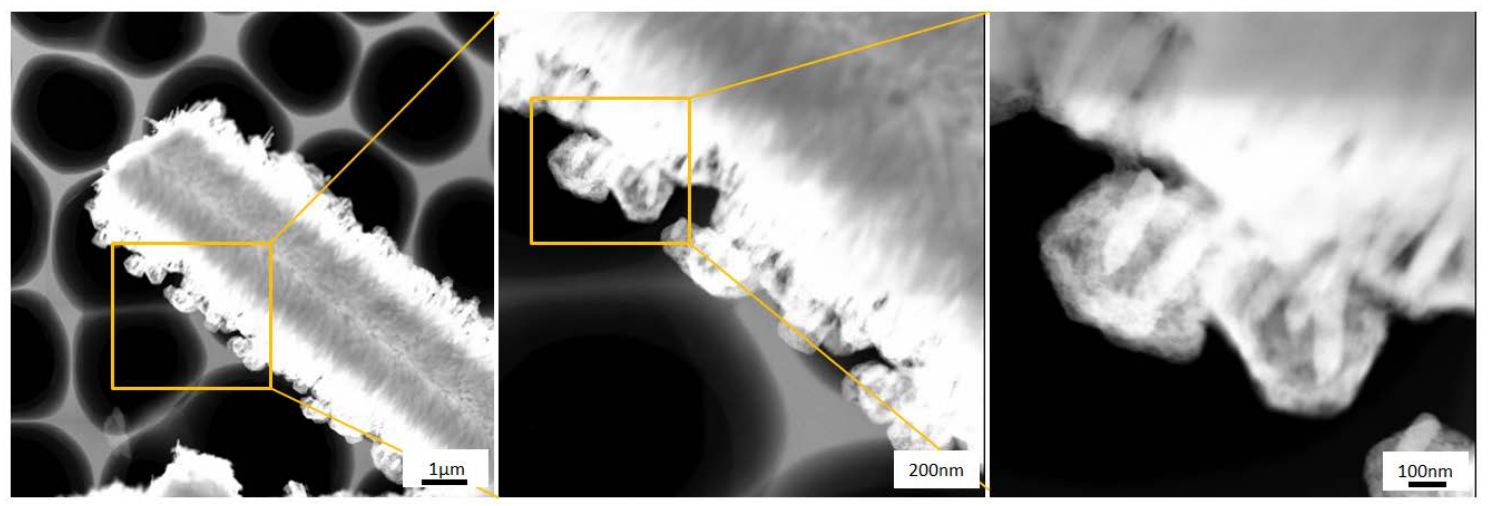

Figure S8. Typical HAADF-STEM images of ZnO@ZIF-8 NWs/3D silicon structures, the zoomed in images show the morphology of ZIF-8 crystal covered ZnO NWs. 